\title{
EPIDEMIOLOGY OF POTATO BLIGHT
}

A MOST successful symposium on factors which affect the severity of potato blight disease was arranged by the British Mycological Society on January 5 at the London School of Hygiene and Tropical Medicine. Dr. R. V. Harris, chairman of the Society's Plant Pathology Committee, presided and introduced six speakers, who together covered a wide range of new knowledge about the disease and its causal fungus, Phytophthora infestans.

Dr. N. F. Robertson, of Cambridge, started from the widely accepted assumption that blight overwinters in the tubers, and that only a proportion of such overwintering tubers gives rise to infected plants. He then directed attention to a delay in the development of stem lesions resulting from inocula. tions early in the year. Although such lesions appeared within seven to fourteen days of inoculation, they did not begin to develop epidemically until some forty days later. This lag between the first infection and the 'real' infection occurred in both greenhouse and field experiments. Inoculations on the young leaves and near the stem apex were more effective than those near the base of the stera. Dr. Robertson posed the questions (1) whether the infection which causes the main epidemic could arise as dispersion from earlier stem lesions, and (2) whether such dispersion could be forecast by survey. There is no doubt about the fact of epidemic blight development, but Dr. Robertson gave an interesting detailed study of the development pattern of an epidemic within a particular crop.

The early phases of potato blight epidemics were considered by Dr. J. M. Hirst, of Rothamsted, with the view of finding reasons for their relative constancy in time. He also presented examples of delayed development of stem lesions, showed that early lesions occurred on only $0-1 \cdot 4$ per cent of the emergent plants, and sought an explanation of the delayed development in a study of the ecoclimate within the crop. Comparisons of such climate with weather conditions in a screen at $4 \mathrm{ft}$. above ground did not indicate large differences, but showed that temperatures generally rose higher in the crop than in the screen during early growth. The relative humidity did not fall so low in the crop newly emerged as it did in the screen, but among slightly older plants the relative humidity might be lower. During the epidemic development of blight, temperatures were about the same in crop as in screen, but the relative humidity was higher in the crop. The concentration of spores of $P$. infestans in the air was also considered and found to be less than 100 per cubic metre until the blight epidemic was well developed. Dr. Hirst envisaged an outbreak of blight as resulting from the removal of successive barriers : (1) foliage must be above ground; (2) fungal infection must arise above ground; and (3) there must be conditions (principally of weather) suitable for infection to take place.

Dr. J. Grainger, of the West of Scotland Agricultural College, advanced an explanation of blight phenology based upon new investigations of hostplant physiology and known influences of weather conditions which affect the parasite. He described field experiments and inoculation tests which showed that the potato plant is very susceptible indeed to attack by Phytophthora infestans in the early stages of growth; then follows a period of very low susceptibility before the second susceptible epidemic stage is reached. The term 'disease potential' was, however, used for these changes, for 'susceptible' and 'resistant' should properly be reserved for the relative tolerance of a species or variety for disease. Several detailed growth-cycle analyses of all parts of the host through its whole cycle of growth showed that the rate of growth was most rapid, and the percentage of total carbohydrate in the whole plant was low, at the time of low disease potential, and vice versa. These two factors, the only consistent ones found, were combined in the $C_{p} / R_{s}$ ratio-the weight of total carbohydrate in the whole plant $\left(C_{p}\right)$ divided by the residual dry weight of the shoot $\left(R_{g}\right)$. The height of this ratio provided a measure of the disease potential, being high when it was high, and vice versa. Very high values of the ratio in the youngest sprouts conferred a hypersensitive disease potential which was for a short time capable of eliminating the disease. Then the ratio (and disease potential) fell rapidly to low values, so that if any blight lesions on the stems or leaves had escaped the hypersensitive phase, they would not develop until the ratio began to rise again (for the time of the summer epidemic). The rate of development of a blight epidemic depends largely on the height of the $C_{p} / R_{s}$ ratio at the time of its first appearance. High-ratio second early crops sustained an early attack of blight in 1955 , while at the same time low-ratio maincrops were not diseased. If crops are planted at different times of the year, they have different ratio values at the time of the usual blight epidemic and are attacked with differing severity but always according to the relative ratio value. Since dormant tubers have moderate $C_{p} / R_{8}$ ratio and disease potential, the ratio provides an index to the host's disease potential for blight at all times of its complete growth cycle.

Conditions which affect the parasite assume major importance at the start of the main epidemic, and Dr. Grainger described the 'Auchincruive' selfcalculating blight forecast recorder. This can be calibrated to record the weather specifications of either Beaumont or Bourke, and a further development was the 'Auchan' blight forecast alarm. Protective spraying according to the first valid forecast always gives maximum performance in areas where protective spraying is economic. Blight appears underground on the tubers soon after it occurs on the foliage ; it frequently appears first on the undersides and seems to have a close relation with the amount of soil moisture.

Weather conditions which presage blight development have been derived either empirically by survey (for example, Beaumont, Bourke), or fundamentally, by laboratory studies of the environmental needs of the fungus (for example, Crosier). Mr. P. M. Austin Bourke, of the Irish Meteorological Service, stated this and added a new approach - the use of synoptic weather charts in forecasting a disease outbreak. 'Blight weather' is provided by an influx of tropical maritime air, and this is given by three types of 
system: (1) a series of wave depressions (in which conditions between the depressions provided suitable weather for practical spraying); (2) a quasistationary front; and (3) a complex 'puddle' low system. On the other hand, a direct outbreak of polar air, with the establishment of a blocking ridge, gave weather which was completely unfavourable for blight development. Mr. Bourke gave details of six sets of conditions in three summer months of 1956, when there was good agreement with other methods of forecasting blight. The dates are rather important, for they were matched by reports from other parts of Britain: June 8-12 and 16-21 ; July 4-8, 13-18 and 29-30; August 15-19. Particular interest attached to the period during July 13-18, which initiated the main blight outbreak in England and Wales, and could have been forecast satisfactorily either by local specification or by the new synoptic method. Mr. Bourke had found his own specification of suitable weather conditions to work in Chile, but pointed out that different regions would probably need different specifications.

Mr. E. C. Large, of the Plant Pathology Laboratory, Harpenden, outlined the results from seven years work on blight forecasting by Beaumont rules, with comparisons of yield build-up and spraying experiments. There had been a useful degree of success, particularly in 1956. It was possible to recognize certain blight years (for example, 1948, 1950, 1953) when there were economic gains from protective spraying. Other years (for example, 1952) had blight so late in the season that there was actually a loss in overall yield from protective spraying, mainly from direct damage caused by the passage of tractor wheels. Protective spraying was not economic in northern England because blight caused so little loss in yield. Timing the spray about one week before blight covered $0 \cdot 1$ per cent of the foliage gave good results in a 'blight year', but spraying when there was more than this amount of disease gave a much poorer performance. Tuber blight losses were large on some varieties, but 57 per cent of crops had less than 1 cwt. of blighted tubers per acre. The average loss was about $3 \cdot 5$ cwt. per acre, but this type of damage was higher in years when blight was severe on the foliage, and was generally higher in the north of England than in the south.

Potato blight control in North America was reviewed by Mr. A. E. Cox, of the Plant Pathology Laboratory, Harpenden. The consumption of potatoes per person per annum is there less than half that in the United Kingdom, and growth of the crop is more specialized. Blight presents a serious problem in Maine, Prince Edward Island, and the maritime provinces of Canada. There is a shorter growing season (averaging 120 days in the United States, as against 160 in Britain) and many crops are lifted while the tops are still green. American growers are therefore interested in haulm-killing materials (sodium arsenite) and methods (rotary beating). The growers are more concerned to control small amounts of blight on the tops than we are in Britain. Sprays have to be given for the control of insect pests such as Colorado beetle, leaf hoppers and flea beetles, so that sprays for blight control are incorporated in this wider programme. Organic fungicides such as the dithiocarbamates are far more widespread than copper sprays to counter blight. Potato rows are 36 in. apart, and tractor wheel guards are used to minimize haulm damage. Sprays are almost invariably at high volume (100 gallons per acre) and are applied to the upper surface of the foliage; no drop lances are used.

Several interesting matters arose from extensive discussions which took place at intervals during the symposium. It appeared that spores of $P$. infestans lose their viability fairly quickly even at relatively high humidities close to the leaf surface. Blight can develop on fields which have not themselves had primary foci of early lesions, and it would scarcely be practical to control primary foci in Britain. More attention should be paid to the elimination of all blighted tubers from stocks of seed, and to the destruction of waste growing tubers, on which stem lesions were frequent. The $C_{p} / R_{s}$ ratio rose initially and later fell in potatoes grown from true seeds, but the rise was not high enough to confer hypersensitivity, as happens in plants grown from tubers.

\section{THE SCIENCE MASTERS' ASSOCIATION}

\section{ANNUAL MEETING}

$\mathrm{B}^{\mathrm{T}}$ ETWEEN seven and eight hundred science masters and guests attended the annual meeting of the Association, held in the University of Cambridge during the first week in January. After an introductory illustrated lecture on Cambridge, by Mr. G. F. Hickson, members were welcomed to the University by Lord Adrian, Master of Trinity College, and the Fellows of the College, who gave a reception in the Great Hall of the College.

The large examination hall of the University was filled to hear the address by the president for this year, Sir Alexander Todd (professor of organic chemistry, University of Cambridge). Sir Alexander said that the English educational system needed to be changed rapidly to meet the demand for more technologists, and quoted striking figures to show the extent to which Britain lags behind the United States and Russia. He thought that we still tend to maintain a system which might have sufficed in the early days of the industrial revolution, and that if this system were adhered to, our economic ruin was certain. "Trade," he said, "now follows the technologist and not the flag."

Sir Alexander thought that specialization in secondary schools might be reduced, so that students who wished later to turn to a scientific career might not be discouraged by having abandoned science at an early age. He commended the Scottish system, of following many subjects up to university standard, as being more likely to produce the required result.

Prof. N. F. Mott, professor of experimental physics in the University of Cambridge, speaking on "Science in the Universities and Schools", also dealt with specialization, and said that university courses including both arts and science subjects are under consideration at Cambridge; thus, for example, Part I of a Tripos might be taken in an arts subject, and Part II in science subjects. An optional postgraduate course is also being discussed. Prof. Mott supported Sir Alexander Todd's plea for less specialization in the sixth forms of schools, and also advocated more school contacts with industry.

An afternoon discussion on "Technical Education and the Schools" was introduced by Dr. K. B. Hutton, headmaster of Hatfield School, the chair 